\title{
Bile induced acute oedematous pancreatitis in rats: non-parallel changes in pancreatic morphology and amylase release in vitro
}

\author{
T Arendt, U Broschewitz
}

\begin{abstract}
Pancreatic morphology and amylase release from isolated pancreatic acini in response to caerulein was studied in the course of an experimental bile induced acute pancreatitis without acinar necrosis. The inflammation was induced by retrograde microinfusion of $25 \mu l$ bile into the rat bile pancreatic duct. A dissociation between functional and structural findings was seen. One hour after the bile injury, there was a transient change in acinar cell function. The response to stimulation by caerulein was reduced by $\mathbf{5 0} \%$, whereas the sensitivity to caerulein was normal. There was oedema and an initial leucocyte infiltration of the gland. Six hours, one day, three days, and seven days after the bile injury, there was an acute interstitial oedematous pancreatitis with a modest polymorphonuclear leucocyte infiltration of the interstitium and widespread acinar vacuolisation. Morphological changes were most pronounced at the third postoperative day. Acinar amylase release, however, was normal both in terms of sensitivity and responsiveness to stimulation. These results show that bile injury may result in an initial disturbance of acinar cell function. Normal acinar amylase release prevailing in the course of the inflammation suggests that disturbance of the acinar amylase secretory response is not a primary stimulant of the inflammation before the development of acinar necrosis.
\end{abstract}

(Gut 1994; 35: 1127-1131)

Bile induced acute pancreatitis is a disease of differing severity, which may vary from a mild interstitial oedematous inflammation to widespread parenchymal destruction. Acinar necrosis resulting from detergent effects of bile salts on cellular membranes, the most serious result of bile induced pancreatic injury, has been extensively described. ${ }^{1}$ The non-destructive effects of bile on acinar cells, however, have received little attention to date. There are no data, in particular, on exocrine enzyme release of viable acinar cells in the early period of bile induced acute pancreatitis, which may be important for the understanding of the pathogenic mechanisms that precede parenchymal necrosis.

In non-destructive experimental acute pancreatitis induced by supramaximal caerulein stimulation of rat pancreatic exocrine secretion, changes in acinar digestive enzyme release in vitro were seen: pancreatic acini were less sensitive to muscarinic agonist stimulation and showed a decrease in the maximal secretory capacity. ${ }^{2}$ It was proposed that changes in acinar stimulus secretion coupling may also be important in other forms of acute pancreatitis and perhaps even in the human disease. ${ }^{3}$ In the early period of bile induced acute pancreatitis, however, no data exist to support this hypothesis.

To date, studies on acinar cell function in bile induced acute pancreatitis have been hampered by the lack of non-destructive models of the disease. We studied the relation between the development of morphological inflammatory lesions of the pancreas and of amylase release from isolated pancreatic acini in a model of bile induced acute pancreatitis without significant acinar necrosis that uses retrograde microinfusion of bile into the rat bile pancreatic duct.

\section{Methods}

\section{MATERIALS}

The following were purchased: highly purified collagenase and $\mathrm{N}$-2-hydroxyethylpiperazine$N^{\prime}$-2-ethanesulphonic acid (HEPES) from Boehringer (Mannheim, Germany), triton X-100 from Ferak (Berlin, Germany), caerulein (Takus) from Farmitalia (Freiburg, Germany), Monotest alpha-amylase and Monotest lactic dehydrogenase-UV from Boehringer (Mannheim, Germany).

ANIMAL MODEL

Fasting female Wistar rats (250-300 g) were anaesthetised with sodium hexobarbitone (80 $\mathrm{mg} / 100 \mathrm{~g}$ bodyweight intraperitoneal) and the abdomen was opened along the midline. The tip of a Hamilton microsyringe was passed through the intact antimesenteric wall of the duodenum into the distal bile pancreatic duct and secured by an encircling suture. A W 101 manometer with attached BMT 401 biomonitor (Messgerätewerk Zwönitz, Zwönitz, Germany) was introduced into the system by a three way tap, for constant monitoring of duct pressure, which was always below $20 \mathrm{~cm} \mathrm{H}_{2} \mathrm{O}$. Infusion into the duct was delivered by a perfusion pump at a constant rate of $1 \mu \mathrm{l} / \mathrm{min}$. During infusion, the duct was ligated near the hilus of the liver. Twenty five $\mu l$ of the solution under study were infused 
into the rat bile pancreatic duct. This volume is known to be accepted by the rat pancreas without the development of unphysiological gross ductal rupture. ${ }^{4}$ Three experimental groups were studied:

Group 1: duct infusion of bile - bile was obtained as described elsewhere ${ }^{5}$ and contained $(\mathrm{mM} / \mathrm{l})$ glycocholate 66.9 , taurocholate $16 \cdot 2$, glycochenodeoxycholate $76 \cdot 3$, glycodeoxycholate $54 \cdot 4$, taurochenodeoxycholate $14 \cdot 5$, taurodeoxycholate $6 \cdot 8$, phospholipids $6 \cdot 2$, and cholesterol $7 \cdot 2$.

Group 2: duct infusion of physiological saline (controls).

Group 3: no duct infusion (sham).

The syringe and the clamp were then removed. The animals were returned to their cages. Rats were anaesthetised again and killed by cardiac section one hour, six hours, one day, three days, and seven days after the completion of the bile pancreatic duct infusion. Pancreatic specimens were prepared as described below.

\section{MORPHOLOGY}

For light microscopy, pancreatic specimens were fixed with $10 \%$ formaldehyde, embedded in paraffin wax, stained with haematoxylin and eosin, and examined in a blinded fashion. Pancreatic tissue was graded for acute pancreatitis according to the presence of oedema, interlobular and intralobular neutrophil infiltration, sialangiitis - that is, inflammatory cell infiltration of the pancreatic duct system, fatty tissue necrosis, acinar vacuolisation, and acinar necrosis. Each of these factors was marked on a scale of 0-3 (absent to severe) and the mean value was calculated.

For electron microscopy, one millimetre cubes of pancreatic tissue were prepared as described in detail elsewhere. ${ }^{6}$ Tissue was fixed with cold $2.5 \%$ glutaraldehyde and $0.1 \mathrm{M}$ sodium cacodylate buffer, postfixed in $1 \%$ OsO4, and embedded in Epon. Thin sections were stained with uranyl acetate followed by lead citrate and examined in a blinded fashion using a BS 613 transmission electron microscope (Tesla, Czechoslovakia).

\section{ENZYME RELEASE OF ISOLATED PANCREATIC} ACINI

Isolated rat pancreatic acini were prepared essentially as described by Williams et al ${ }^{7}$ using collagenase digestion and gentle shearing forces. Acini $(0.5 \mathrm{ml})$ were suspended in an incubation solution $(1.5 \mathrm{ml})$, which contained 0.1 M HEPES enriched with minimal Eagle's medium amino acid supplement in the presence of various doses of caerulein and incubated for 30 minutes. Then $0.2 \mathrm{ml}$ of the suspension was centrifuged at $10000 \mathrm{rpm}$ for one minute in a microcentrifuge and the supernatant assayed for amylase and lactic dehydrogenase activity. Lactic dehydrogenase, an intracellular, non-secretory enzyme, was assayed to distinguish a detergent action of bile from a specific releasing effect. Amylase

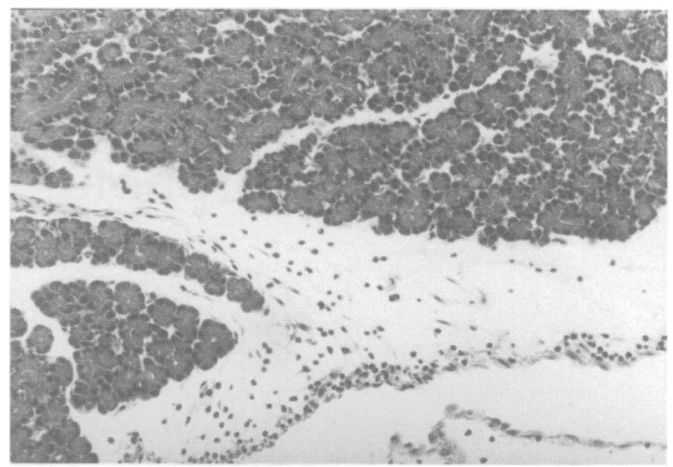

Figure 1: Rat pancreas one hour after bile microinfusion. Oedema and initial polymorphonuclear leucocyte infiltration of the interstitium (haematoxylin and eosin, original magnification $\times 250$ ).

activity was assayed using $p$-Nitro-phenyl-a D-maltoheptaosid as a chromogenic substrate. Before incubation, some aliquots of acini $(0.5 \mathrm{ml})$ were added to $1.5 \mathrm{ml}$ incubation solution, followed by an immediate centrifugation. The activities of amylase in these aliquots were taken as the initial time zero value. This value was subtracted from values obtained after incubation. At the same time, some aliquots of acini were homogenised by adding $0.2 \mathrm{ml} 5 \%$ (vol $/ \mathrm{vol}$ ) triton $\mathrm{X}-100$ to the incubation solution followed by assay of total tissue enzyme activity. Enzyme release was calculated by expressing the activity in the medium as a percentage of total enzyme tissue content. Total enzyme content of pancreatic tissue was expressed as total enzyme activity/mg dry weight.

SURVIVAL

Survival time was measured over a period of seven days using 15 rats in each of the three experimental groups.

\section{STATISTICAL ANALYSIS}

The Mann-Whitney rank sum test was used to assess differences between groups. Data are expressed as mean (SEM).

\section{Results}

\section{MORPHOLOGY}

Group 1

One hour after intraductal bile infusion, a modest oedema was found. Few polymorphonuclear leucocytes were scattered in the interlobular interstitium of the pancreas (Fig 1); the inflammatory score (IS) was 0.4 ( $>0.05 v$ groups 1 and 2 ).

Six hours, one day, and three days after intraductal bile infusion, acute interstitial oedematous pancreatitis was seen. The inflammation spread from the ductal connective tissue, which showed a severe sialangiitis (Fig 2). There was a modest interlobular and a focal intralobular polymorphonuclear leucocyte infiltration and occasional fatty tissue necrosis. Acinar cell vacuolisation was widespread (Fig 3). 


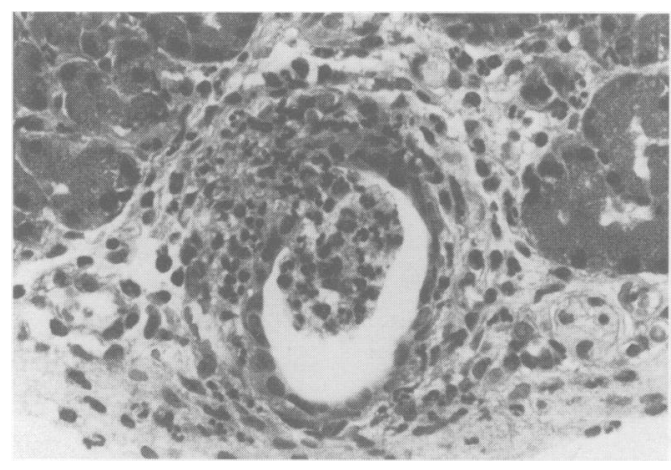

Figure 2: Rat pancreas one day and three days after bile microinfusion. Inflammatory cell infiltration of an interlobular duct (haematoxylin and eosin, original magnification $\times 430$ ).

Autophagic vacuoles within acinar cells occasionally contained zymogen granules (Fig 4). Cellular organelles believed to be zymogen granules containing electron dense material were found in the interstitial space in a few specimens (Fig 5); zymogen discharge at the basolateral acinar cellular membrane was not seen. Focal necrosis of acinar cells was an exceptional finding. The IS after six hours, one day, and three days of bile injection was $0.9(0.2), 1.2(0.3)$, and $1.3(0.3)$ respectively $(p<0.05 v$ groups 1 and 2$)$. Seven days after intraductal bile infusion, the morphological changes declined and a focal residual interstitial inflammation with ductular transformation of the acinar tissue was found (IS: $0.7 ; \mathrm{p}<0.05 v$ groups 1 and 2) (Fig 6).

\section{Group 2}

One hour after intraductal saline infusion, a modest oedema and a mild interlobular polymorphonuclear leucocyte infiltration of the gland was seen (IS: $0.3(0.1)$ ). Six hours and one day after the saline infusion, the pancreas showed a residual focal polymorphonuclear leucocyte infiltration of the interstitium (IS: 0.2 respectively). At three days and seven days, the gland was inconspicuous.

\section{Group 3}

One hour, six hours, and one day after the sham operation, a mild oedema of the pancreas was seen (IS: $0 \cdot 2$ ). At three days and seven

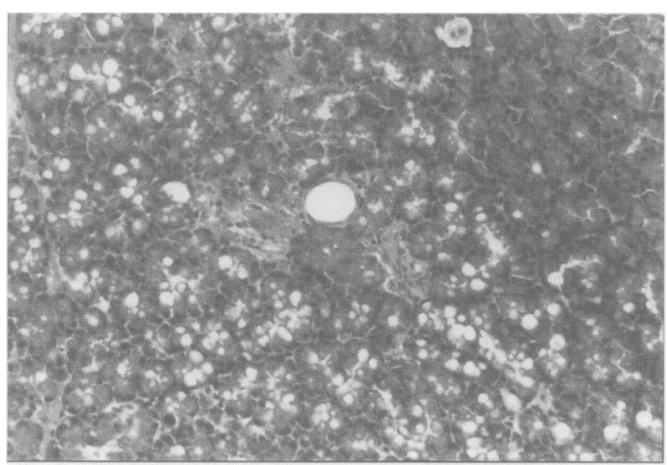

Figure 3: Rat pancreas one day and three days after bile microinfusion. Widespread acinar vacuolisation

(haematoxylin and eosin, original magnification $\times 315$ ).

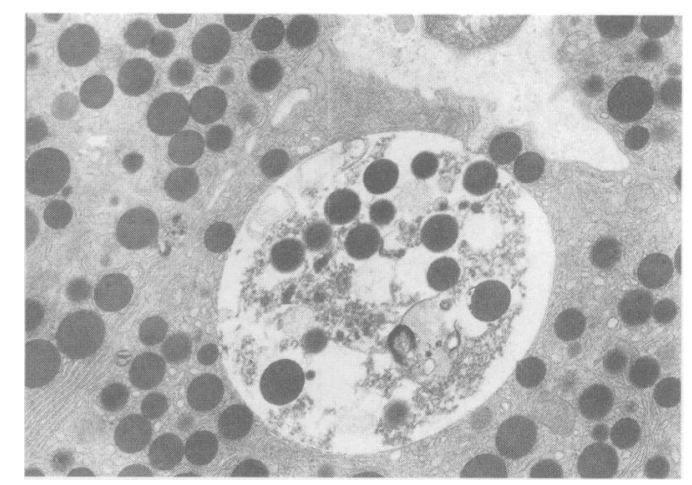

Figure 4: Rat pancreas one day and three days after bile microinfusion. Acinar cell with an autophagic vacuole containing degraded cellular organelles including zymogen granules (original magnification $\times 9450$ ).

days, no morphological changes in the gland were found.

\section{EXPERIMENTS IN VITRO}

Amylase release one hour after duct infusion Basal amylase release was similar in all experimental groups studied. In bile injected rats, acinar amylase release was $4 \cdot 8(9 \cdot 6) \%$ of total content and in saline injected controls and sham operated animals basal secretions were $5 \cdot 0(0 \cdot 8) \%$ and $5 \cdot 2(0 \cdot 7) \%$ respectively (Fig 7). Lactic dehydrogenase activity measured in these same conditions was low (data not shown) and showed no significant differences between groups. These findings confirm the integrity of the acini with which we have been working.

When the amylase release was studied as a function of the concentration of caerulein, the sensitivity of the acini from bile injected rats was not modified. In all groups studied, the minimal and the maximal effective concentration of caerulein for amylase release were 1 and 75 pmol respectively. The maximal secretory response to caerulein was, however, significantly reduced in bile injected rats as acini from these animals released only 11.7 $(0.9) \%$ amylase $(p<0.05 v$ groups 1 and 2$)-$ that is, a $2 \cdot 5$-fold stimulation of amylase release, whereas saline injected controls and sham operated animals released $21.8(2 \cdot 0) \%$

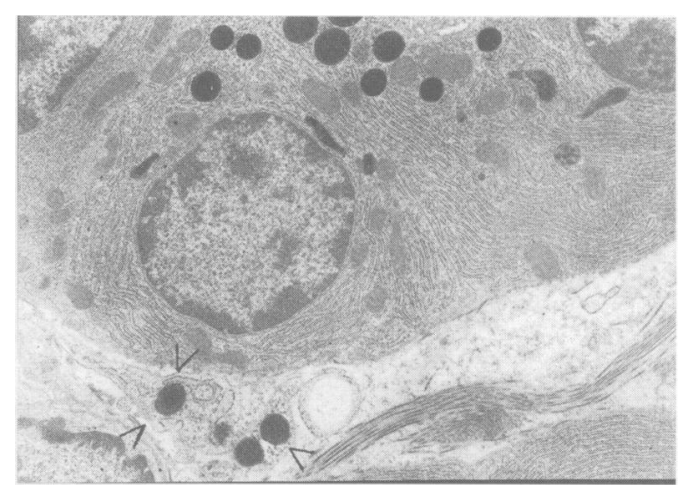

Figure 5: Rat pancreas one day and three days after bile microinfusion. Pancreatic interstitium: process of $a$ macrophage (arrowheads) adjacent to an acinar cell containing electron dense material believed to be zymogen granules (original magnification $\times 9450$ ). 


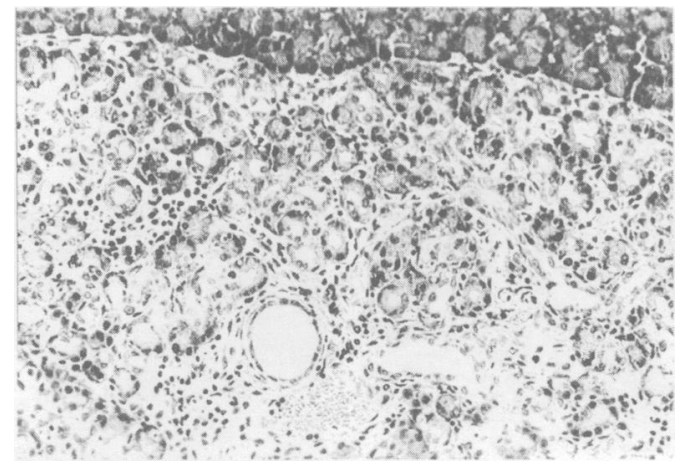

Figure 6: Rat pancreas seven days after bile microinfusion. Focal residual interstitial inflammation with ductular transformation of the acinar tissue (haematoxylin and eosin, original magnification $\times 330$ ).

and $23.3(3 \cdot 1) \%$ respectively - that is, had a fivefold stimulation of amylase release. Acini from all experimental groups showed reduced amylase release at supramaximal concentrations of caerulein.

Amylase release six hours, one day, three days, seven days after duct infusion

Dose response studies of amylase release from acini prepared at later intervals showed that the maximal secretory capacity in bile injected rats had already returned to normal six hours after the bile injury and that both basal and stimulated amylase release were

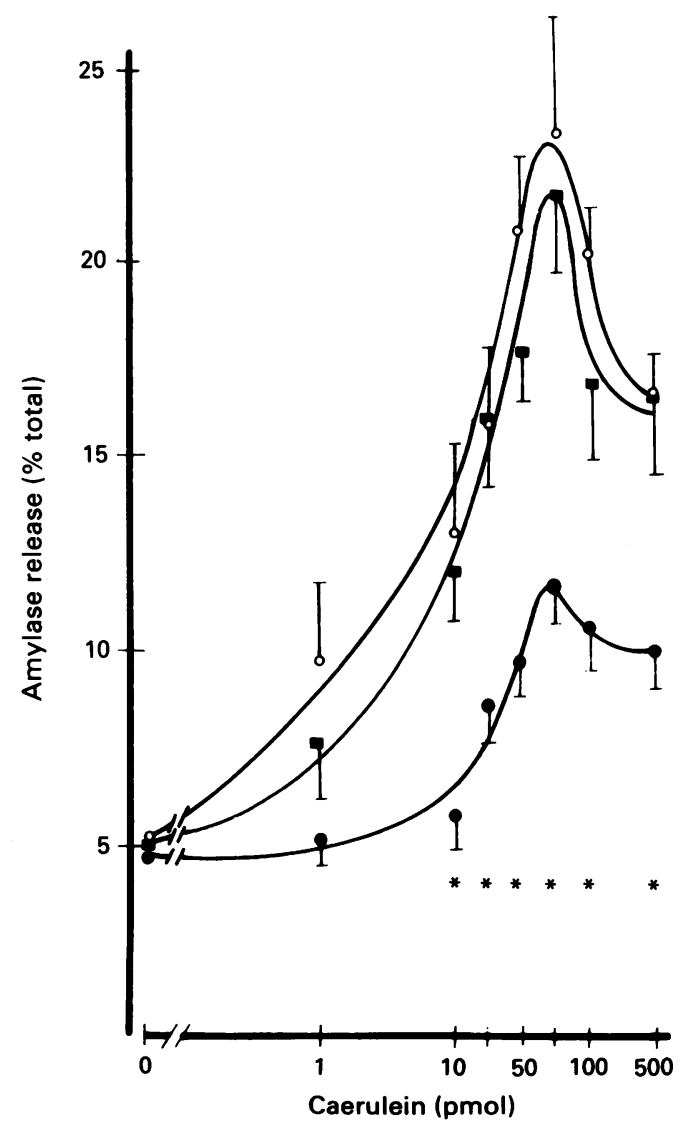

Figure 7: Effect of bile microinfusion into the rat bile pancreatic duct on the dose response curve of acinar amylase release to caerulein. Acini were prepared one hour after the bile injury. Results are the means of five experiments. $O=$ sham; $:$ = controls; $\bullet=$ bile microinfusion; $\star=$ bile microinfusion $\mathrm{v}$ sham and controls, $p<0.05$, Mann-Whitney rank sum test. indistinguishable from controls at all intervals studied (data not shown).

Amylase content of pancreatic tissue

Total amylase tissue activity/mg dry weight did not change in the course of acute pancreatitis in bile injected rats, and showed no significant differences compared with saline injected and sham operated controls at all intervals studied (data not shown).

\section{Survival}

In the three experimental groups studied, all rats survived the total period of observation.

\section{Discussion}

We describe a model of acute oedematous pancreatitis without significant acinar necrosis after bile microinfusion into the rat bile pancreatic duct. The inflammation was induced under circumstances as similar as possible to those that would be likely to occur after biliopancreatic reflux in humans. Firstly, bile was infused into the rat pancreas to avoid unphysiological damaging effects of individual bile salts on the pancreatic duct system. ${ }^{8}$ Secondly, the quantity of fluid infused into the rat bile pancreatic duct was $<50 \mu \mathrm{l}$ - that is, in the range of what is accepted by the pancreatic duct system without gross ductal rupture. ${ }^{4}$ Thirdly, duct pressure was monitored and constantly kept within the physiological range. Thus, bile microinfusion into the rat pancreas is probably more similar to the clinical disease than the commonly used rat model of taurocholate induced acute pancreatitis with retrograde injection volumes grossly in excess of possible reflux and without regard to duct pressure, ${ }^{4}$ from which most data are derived on the disturbance of acinar cell structure ${ }^{1}$ and function ${ }^{9}$ in the course of acute pancreatitis.

Supporting this contention, morphological lesions were seen that resemble those seen in early human acute pancreatitis, ${ }^{1011}$ but do not occur during the rapid, uniform destruction of the gland in taurocholate induced acute pancreatitis, ${ }^{1}$ such as spread of the interstitial polymorphonuclear leucocyte infiltration (Fig 1) from the ductal connective tissue (Fig 2) and vacuolisation of acinar cells (Fig 3). Another advantage over taurocholate induced acute pancreatitis is the wide range of disease activity seen. Ultrastructural data suggest that the inflammation stopped not far from conversion to parenchymal destruction. Firstly, there was degradation of zymogen granules within autophagic vacuoles of acinar cells (Fig 4). This is noteworthy because intra-acinar colocalisation of lysosomal and exocrine digestive enzymes is a precondition for trypsin activation by the lysosomal enzyme cathepsin B, which is believed to cause acinar necrosis in some forms of experimental acute pancreatitis. ${ }^{12}$ Secondly, acinar organelles were occasionally found in the interstitial space (Fig 5) pointing to a focal disruption of acinar cellular membranes. 
In the course of bile induced acute pancreatitis, we saw a dissociation between changes in pancreatic morphology and amylase release in vitro. In an initial phase studied one hour after the bile injury, pancreatic acinar cell function was significantly changed: acini had the same sensitivity in terms of minimal and maximal effective concentration of caerulein as controls, but their responsiveness to the secretagogue was reduced by $50 \%$. At the same time, morphological investigation showed only an oedema and an initial leucocyte infiltration of the interstitium that was not significantly different from controls. In a second phase, which lasted throughout the experiment until the regression of the inflammation, amylase release from pancreatic acini was similar to controls both in terms of sensitivity and responsiveness to caerulein stimulation, while an acute interstitial pancreatitis with a modest polymorphonuclear leucocyte infiltration of the interstitium and widespread acinar vacuolisation was present.

Disturbance of pancreatic acinar digestive enzyme release in the initial phase of the experiment occurred before any significant leucocyte infiltration of the interstitium and, therefore, apparently does not result from secretions of activated leucocytes. Bile salts also were probably not harmful because, in contrast, a specific stimulatory effect on digestive enzyme release from pancreatic acini in vitro was seen at concentrations that do not cause acinar necrosis. ${ }^{13}$ Perhaps, inflammatory mediators such as prostaglandins might be involved, which have been reported to impair the secretory capacity of isolated rat pancreatic acini in response to cholecystokinin stimulation. ${ }^{14}$

After the initial reduction of the secretory capacity, however, pancreatic acinar exocrine enzyme release was noticeably undisturbed throughout the period of observation. The preservation of normal acinar stimulussecretion coupling in non-destructive bile induced pancreatitis is in striking contrast with findings in caerulein induced acute oedematous pancreatitis. ${ }^{2}$ There, a change in acinar digestive enzyme release is assumed to play a causative part in the initiation of the inflammation, ${ }^{15}$ as a persistent impairment of both acinar sensitivity and responsiveness to stimulation was found to be associated with a concomitant leucocyte infiltration of the interstitium. ${ }^{2}$ In non-destructive bile induced acute pancreatitis, the association of normal acinar stimulus secretion coupling prevailing in the course of the inflammation and a progressive leucocyte infiltration of the interstitium shows that bile injury of the pancreas results in an inflammatory response within the interstitium, irrespective of acinar digestive enzyme secretion. We conclude that disturbance of exocrine enzyme release of pancreatic acinar cells as judged by their amylase secretory response is probably not the primary stimulant of the inflammation before the development of acinar necrosis in this model.

We are indebted to Dr sc Letko, Magdeburg, for generously providing training opportunities for the acinar preparation technique in his laboratory. We wish to thank Mrs Schier and Mrs Vetterlein for expert technical assistance.

1 Aho HJ, Nevalainen TJ. Experimental pancreatitis in the rat. Ultrastructure of sodium taurocholate-induced pancreatic lesions. Scand $f$ Gastroenterol 1980; 15: 417-24.

2 Morisset J, Wood J, Solomon TE, Larose L. Muscarinic receptors and amylase secretion of rat pancreatic acini during caerulein-induced acute pancreatitis. $\mathrm{Dig} \mathrm{Dis} S \mathrm{~S} i$ 1987; 32: 872-7.

3 Niederau C, Ferell LS, Grendell JH. Caerulein-induced acute necrotizing pancreatitis in mice: protective effects of proglumide, benzotript, and secretin. Gastroenterology proglumide, benzotript

4 Armstrong CP, Taylor TV, Torrance HB. Pressure, volume and the pancreas. Gut 1985; 26: 615-24.

5 Arendt T. Bile-induced acute pancreatitis in cats: roles of bile, bacteria and pancreatic duct pressure. Dig Dis Sci 1993; 38: 39-44.

6 Arendt T. Penetration of lanthanum through the main pancreatic duct epithelium in cats following exposure to infected human bile. Dig Dis Sci 1991; 36: 75-81.

7 Williams IA, Kore M, Dormer KC. Action of secretagogues on a new preparation of functionally intact, isolated pancreatic acini. Am $\mathcal{F}$ Physiol 1978; 235: E517-24.

8 Reber HA, Adler G, Wedgwood KR. Studies on the perfused pancreatic duct in the cat. In: Go VLW, ed. The exocrine pancreas: biology, pathobiology and diseases. New exocrine pancreas: biology, pathobiolog

9 Niederau C, Niederau M, Lüthen R, Strohmeyer G, Ferrell LD, Grendell JH. Pancreatic exocrine secretion in acute experimental pancreatitis. Gastroenterology 1990; 99: $1120-7$

10 Foulis AK. Histological evidence of initiating factors in acute necrotizing pancreatitis in man. $\mathcal{f}$ Clin Pathol 1980; 33: $1125-31$

11 Klöppel G, Dreyer T, Willemer S, Kern HF, Adler G. Human acute pancreatitis: its pathogenesis in the light of immunocytochemical and ultrastructural findings in acinar cells. Virchows Arch A Pathol Anat Histopathol 1986; 409: 791-803.

12 Kioke H, Steer ML, Meldolesi J. Pancreatic effects of ethionine: blockade of exocytosis and appearance ethionine: blockade of exocytosis and appearance of crinophagy precede

13 Duan RD, Erlanson-Albertsson C. Effect of bile salt on amylase release from rat pancreatic acini. Scand $\mathcal{f}$ Gastroenterol 1985; 20: 1239-45.

14 Ogami Y, Kimura T, Nawata N. Role of prostaglandin E2 in stimulus-secretion coupling in rat exocrine pancreas. Pancreas 1990; 5: 598-605.

15 Lampel $M$, Kern HF. Acute interstitial pancreatitis in the rat induced by excessive doses of a pancreatic secretagogue. Virchows Arch A Pathol Anat Histopathol 1977; 373: 97-117. 